\title{
Using Technology to Teach Multicultural Literature
}

\author{
Paramita Ayuningtyas, English Departmentt, Bina Nusantara University, Jakarta, Indonesia, paramita@binus.ac.id \\ Andreas Akun, English Departmentt, Bina Nusantara University, Jakarta, Indonesia, akun@binus.edu \\ Retnowati, English Departmentt, Bina Nusantara University, Jakarta, Indonesia, retnowati pareanom@yahoo.com
}

\begin{abstract}
With the help of technology development in communication and transportation, people all around the world now get even more connected and manage to move around easily. This condition enables the formation of a multicultural society, in which people who have different traditions, religions, languages, and customs can inhabit the same space together. However, a multicultural society comes with enormous challenges because conflicts might occur when differences collide and cannot be compromised. Therefore, it is important to deal with these potential conflicts by introducing multicultural discourses to young generation. One possible method is through multicultural literature that reflects the condition of a multicultural society. This study offers some methods of utilizing technology to teach multicultural literature. It also investigates English students' perceptions toward multicultural literature as part of the curriculum in English major. The data were taken from questionnaires given to English-majored students from Bina Nusantara University, Indonesia, and Aletheia University, Taiwan. The obtained data were later analyzed both quantitively and qualitatively. The result shows how students from both universities need to be motivated more to study literature from underrepresented literary scenes. It is expected that the inclusion of technology in teaching multicultural literature will help them to engage more in the courses.
\end{abstract}

Keywords-diversity, English major, multicultural literature, multiculturalism, technology

\section{INTRODUCTION}

The rapid development of technology in the 21st century, particularly communication and means of transportation, has helped people all around the world get more connected and move across the borders conveniently. This condition enables the formation of multicultural society, in which people who hold different traditions and values, have different religions, and speak various languages can co-exist in the same space. Multiculturalism is not a new phenomenon; in fact, it has existed since the period of colonization when Europeans went around the globe and landed in countries in Africa, Asia, and America. However, multiculturalism has become even more popular in the last few decades because the application of the concepts in society comes with enormous challenges. Developed countries like United States of America, Canada, and England have witnessed how horizontal conflicts might occur when differences collide and cannot be compromised. It turns out it is not easy to maintain the diversity in a 'bowl of salad'.

As a country which consists of 300 ethnics groups that speak over 700 languages, Indonesia also has been facing many obstacles which could threaten the country's multicultural ideology. Political conflicts during the General Election in 2014 and 2019 and intolerance issues in a number of cities have threatened the unity of the people, and it is worsened by the polarization and hoaxes amplified in social media. Therefore, important steps need to be taken to introduce multicultural discourses that appreciate and promote differences, especially to younger generation.

One possible method to introduce diversity to young generation is through multicultural literature, defined by Yokota as literature that focuses on people of colour from diverse cultural, linguistic and religious groups [1]. Furthermore, according to Taufiq, it is important to study multicultural literature as it reflects dynamic cultural relations and social problems that reflect a multicultural society [2]. Additionally, Brinson stated that multicultural literature are 'mirror' books and 'window' books because through which children can learn not only about their culture but also other cultures that differ from their own [3]. Nevertheless, incorporating multicultural literature in learning material needs proper preparation. Students' initial understanding about multiculturalism also need to be studied first in order to determine what types of reading material suitable for classroom context.

In Indonesian context, multicultural literature has been discussed in a number of academic articles. Taufiq in his 2014 article studies multicultural literature and its relation to identity construction. He examined how multicultural literature can be studied to find out how identity problems reflected in literature are related to nationality. Another research is from Hakim, who analyzed multicultural issues in Indonesian children's books [4]. My research will be different in a way that it offers methods of teaching multicultural literature using technology.

Firstly, this study investigates students' perceptions toward multicultural literature as part of the curriculum in English department. It aims to know responses from specifically English-majored students because through English, the students have a great opportunity to encounter many choices of multicultural literature that portray 
marginalized or underrepresented groups of people in society. The data were collected from questionnaires given to English Department students in two universities: Bina Nusantara University in Indonesia and Aletheia University in Taiwan. After that, this research presents several technology applications that can be incorporated in courses about multicultural literature.

\section{RESEARCH METHOD}

Before discussing the technology applications, this study would like to know first students' understanding and interest about multicultural literature. Questionnaires are used as the instrument to collect the responses. The questionnaires were distributed to English-majored students in Bina Nusantara University in Indonesia and Aletheia University in Taiwan from August to October 2020 and the students' age is ranging from 18 to 23 years old. Participants from Bina Nusantara University for this research are English-majored students who have taken Literary Criticism class (given in semester 5); thus, it is safe to assume that they have been introduced to literary and critical theories.

There are four questions discussed in this research and three of which are in a form of questions with multiple choices. The closed-ended questions are as follow: (1) Multicultural Literature is defined as " $a$ body of literature that spans all literary genres but generally focuses on primary characters who are members of underrepresented groups whose racial, ethnic, religious, sexual orientation, culture historically has been marginalized or misrepresented by the dominant culture" (Lawson) [5]. How eager (longing, desiring) are you to study and enjoy Multicultural Literature?; (2) Do you think multicultural literature (non-mainstream, literature of the underrepresented) help you understand other fellow human beings in and beyond the nations?; and (3) If you are free to choose the literary texts to study at school/university, which one will you like most?

The fourth question analysed in this research is an open-ended question, which is in your personal opinion, how can we positively navigate (manage) diversity in our own life? The purpose of this open question is to find out what ways or methods students think can be used to deal with differences in their life. Through this question, it is expected students can make a reflection about their own environment in particular and society in general.

After the data had been collected, the answers to the closed questions were calculated and the result was presented in pie charts. Next, the complete data were analysed by using concepts of multiculturalism and multicultural literature. To achieve the goal of this research, books and academic articles discussing the related concepts were used as references. Since this research focuses on a small group of respondents (19 students from Bina Nusantara University, later referred as Binus, and 13 students from Aletheia University), it does not intend to generalize the perceptions of all English-majored students. Also, it should be noted that the result is still general and basic. However, the result of this research can be a starting point for further research with bigger objectives and more numbers of participants.

\section{RESULT AND DISCUSSION}

This part of the paper presents the result of the questionnaires and the discussion and interpretation of the data. In the bio section of the questionnaires, participants were also asked to mention their hometown and their ethnicity and later, it will be seen in what way this information will determine their responds to the open-ended question. For Binus University students, they will be referred to with their initials and Aletheia University students as AU-(number).

In question number one, participants were asked how eager they are to study and enjoy multicultural literature. Five options are given in this question and the result from Binus University participants are: A. $100 \%$ (3 students); B. 75\% (8 students); C. 50\% (7 students); D. 25\% (1 student); and E. 0\% (0 student). The result shows how only three out of 19 students who are completely eager to learn about multicultural literature. Meanwhile, the result from Aletheia University students shows only one student who is willing to study multicultural literature: A. 100\% (1 student); B. 75\% (2 students); C. 50\% (7 students); D. 25\% (1 student); and E. $0 \%$ (1 student). The answers from both universities display that not all students are fully interested in learning more about multicultural literature.

The next question would like to know whether the students think multicultural literature can help them understand other human beings in and beyond the nation. There are only three options provided for this question: A. Yes; B. No; and C. Don't know. Most of Binus University students chose option A (17 out of 19 students) and two students answered that they did not know. This result indicates how they are already aware of the function of multicultural literature as "window" books, the term coined by Brinson. Similarly, most of the respondents from Aletheia University also agree that multicultural literature has the ability to help them understand other human beings. Nine students chose option A and four students answered that they did not know. Although only a small number of participants show $100 \%$ enthusiasm to study multicultural literature, most of them seem to display awareness about the mind-broadening benefit of reading multicultural literature.

Moving on to the result of the next question, Fig. 1. displays the answers from Binus University students about their choice of literary text in classroom. Usually, in introductory literary courses (known as Literature and 
Event: The Nature of Fiction in Binus' curriculum), students are asked to read Western canon literary texts, for example The Story of an Hour by Kate Chopin and The Necklace by Guy de Maupassant. This question would like to find out if they are given an opportunity to determine what to read in classrooms, what kind of literary text they would choose. It turns out that almost $80 \%$ of the participants from Binus University (15 students) are interested in reading both mainstream Western texts and non-mainstream texts from other continents like Asia and Africa. Only three students (15.78\%) who chose to read only mainstream Western texts. This signifies their interest to know non-mainstream texts that rarely receive spotlights in Western canon and it could be a good start for them to be introduced to multicultural literature.

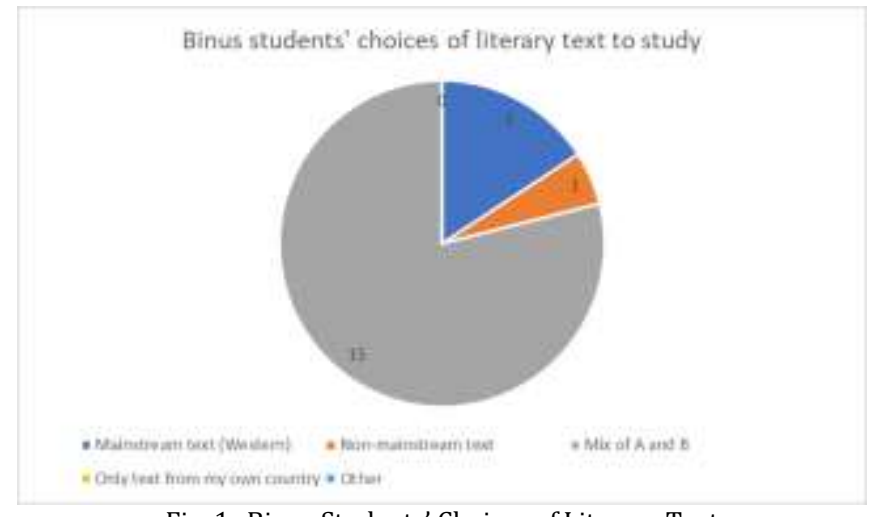

Fig. 1. Binus Students' Choices of Literary Text

More than half of Aletheia students also show eagerness in learning not only mainstream Western texts but also non-mainstream texts, as displayed in Fig. 2. Seven out of thirteen students chose option C, which refers to the combination of mainstream Western texts and underrepresented texts from Asia and Africa. Interestingly, two students chose option D, which means they only want to read texts from their own country. This needs further investigation, but the reason for this might be related to the fact that foreign literature is written in other letters. On the other hand, if we compare it to the data from Binus University, no participant from Binus University answered that they wanted to read texts from their own country.

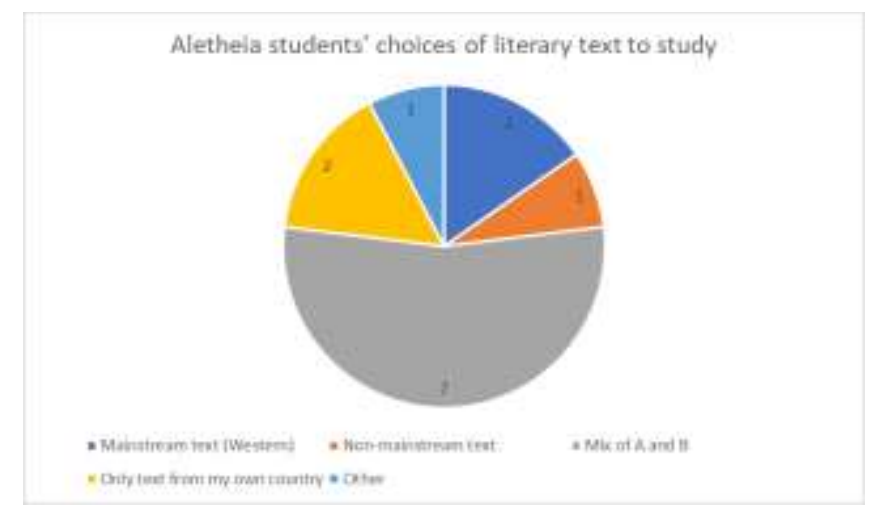

Fig. 2. Aletheia Students' Choices of Literary Text

In Fig. 3, we can see the result for question number three, whether they think multicultural literature has the potential to help them understand other fellow human beings in and beyond the nation. Seventeen participants from Binus University (almost 90\%) chose option A which is 'yes' and two students answered that they did not know. On the other hand, $69.2 \%$ from Aletheia respondents chose A, while the rest of them expressed uncertainty toward that particular function of multicultural literature. Boles mentioned that multicultural literature can be used as an instrument to open students' mind and helps to stimulate an understanding of diversity [6]. The survey result points out that most of the participants are aware of this potential of multicultural literature, that it will help them understand other human beings whose culture can be entirely different from their own. 


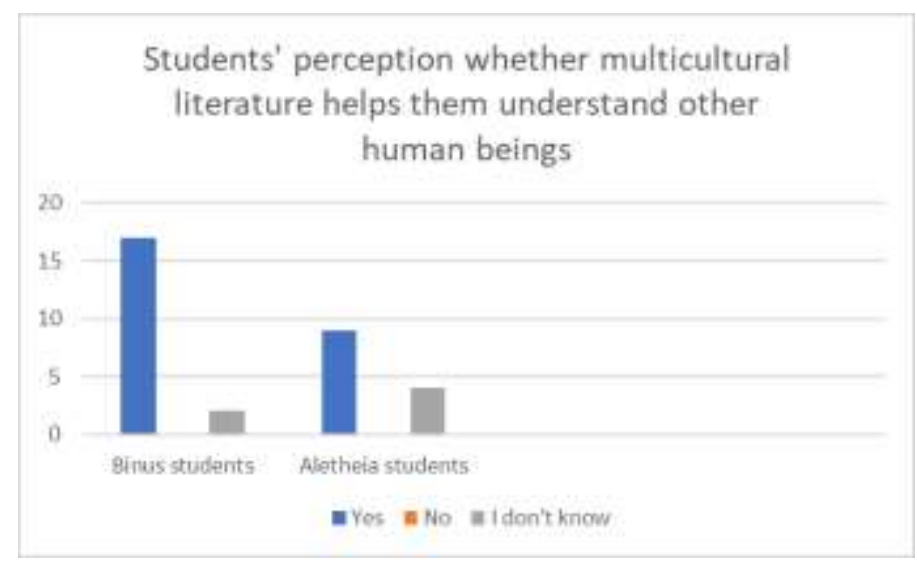

Fig. 3. Students' Answers about the Function of Multicultural Literature

In the open-ended question, respondents were asked in what way they can manage diversity in life. When answering this question, we expected they would also reflect on their own experience as a student living in a diverse environment like Jakarta. Answers from two Binus participants and two from Aletheia will be analysed in this part.

The two respondents from Binus, JY and TS, come from two different cultural backgrounds. JY (male, 23) identifies himself as a Chinese, meanwhile TS (female, 22) categorizes herself in Sundanese, Javanese, Acehnese, and Ambonese ethnic groups. When asked what possible way they can use to manage diversity in life, TS responded, "Be open-minded about it and always see things from different perspectives (not only from ours)." She did not include any of her personal experience and did not mention her cultural background in her answer. In contrast, JY shared his experience as part of a minority group in his answer:

.... Although I am looked as Chinese descent, I still looked [at] myself as Indonesian. Although sometimes I was hated as a Chinese and Christian, I'm trying to love other beliefs, and ethnicities. I'm trying hard to respect others when people don't respect me. I'm trying to forgive their mistakes and weakness, when people blame me. I'm trying hard to listen their arguments, their sadness, anger, when other don't listen. Praising other cultures by listening to their opinions and ideas and not judging them negatively.

JY stated that as a Chinese and Christian in Indonesia, he often became the object of hatred. However, despite his identification with his ethnic group, he still looked at himself as an Indonesian. National identity is a significant part of his identity as well.

If Binus respondents do not seem to have any difficulties to mention their ethnic groups, students from Taiwan on the other hand left the space blank or they simply answered that they did not know. A number of students also simply answered that they are Taiwanese. Which ethnic groups they belong to do not seem to be a major concern for them, different from participants from Binus University who easily categorized themselves into certain ethnic groups in Indonesia. When asked what method they can do to navigate diversity in life, AU-10 (gender unrevealed, 20) stated that we need to "share ourselves experience and culture to everyone". Meanwhile, AU-11 (gender and age unrevealed) answered that instead of learning only through books, "... we have to go outside to see other things." In their answers, they do not include their own personal experience.

The next part of this paper will discuss various technology applications that can be utilized to teach multicultural literature. In introducing and promoting multicultural values, technology can be used as it has the ability to link diverse cultures by reducing temporal and spatial separation [7]. Technology also has to potential to help in teaching multicultural literature so that students not only can understand the intrinsic elements in texts, but they can also explore the issues more deeply and interact more with people from other cultural backgrounds.

The first platform that can be utilized is Youtube. As a free platform, students can maximize their learning process by watching videos that are relevant to the topic discussed in classrooms. Verified channels, for example Tedx Talk, provide videos of experts discussing multiculturalism and diversity both in general and in specific contexts. This can be a start for students to understand the general concepts of multiculturalism. In teaching multicultural literature, after students finished reading the text, lecturers can ask them to enrich their understanding about a certain culture by watching videos in Youtube. Students then can be asked about whether there is a gap between the portrayal of the culture in the text and the portrayal in the video, and in what way different perspectives can lead to different kinds of representation. Another way to use Youtube in teaching multicultural literature is, instead of writing paper all the time, students can upload their videos presenting their 
interpretation and understanding about the text. Besides being stimulated to understand diversity through various multicultural text, students can also express themselves through this method.

The next application that can be used is Instagram. With its current various features, students now can use Instagram to post their creative assignment, such as posters and photos. With the students from Taiwan, students from Indonesia can collaborate in making posters about multicultural literature. By using the correct hashtags (for example \#multiculturalism and \#diversity), their works can be seen by people from various countries and cultural backgrounds and interaction can be built. This will increase students' awareness about other cultures and also help them cooperate with students with different cultural backgrounds as well.

The last technology application that will be discussed is Padlet. Padlet is a virtual bulletin board in which students can curate the information they find on the internet. Using Padlet will not only enhance students' curation skill but also their creativity, as they can also organize their Padlet posts in a versatile way. After reading the chosen multicultural text, students can be assigned to collect photos, websites, videos, or any information about the culture discussed in the text. This is another learning method that can help increase students' awareness and appreciation to diversity of cultures. Padlet can also be utilized for collaborative creative assignments.

\section{CONCLUSION}

Living in a multicultural society is challenging because we will always encounter differences that might trigger both personal and social conflicts. Indonesia, with its tremendous diversity, has also been facing conflicts related to intolerance. Greater actions need to be taken to avoid more intolerance problems in the future.

In academic context, one method to introduce multicultural discourses to students is through multicultural literature. The analysis of the data (taken from a set of questions distributed to English-majored students from Binus University and Aletheia University) shows how students from both universities need to be motivated more to learn literary texts not only from Western canon but also from underrepresented literary scenes. Fortunately, most of the respondents (almost $90 \%$ for Binus and 69.25 for Aletheia) are aware about the function of multicultural literature as a 'window' that introduces them to other cultures and helps them to understand other human beings.

Based on what we have studied in this small research, it is hoped that the use of technology can help improve students' interest in studying multicultural literature. As previously discussed, Youtube, Instagram, and Padlet can be incorporated in teaching and learning materials. Technology has been an essential element in the $21^{\text {st }}$ century society and through various applications, young people can have the opportunity to learn deeply about various issues in multicultural society such as identity, hybridity, power relation and tolerance. Through this small step, they can start developing an understanding toward differences and bringing it into their everyday social practices.

\section{REFERENCES}

[1] R. G. Salas, F. Lucido, and J. Canales, “Multicultural Literature: Broadening Children’s Experience," Texas, 2002.

[2] A. Taufiq, "Multicultural Literature: The Identity Construction in Indonesian Novels," Humaniora, vol. 26, pp. 22-31, 2014.

[3] S. Brinson, "Knowledge of Multicultural Literature among Early Childhood Educators," Multicult. Educ., vol. 19, no. 2, pp. 30-33, 2012.

[4] H. Herdiana, "Multicultural Literature in Indonesian Children’s Books," 2015.

[5] M. Lawson, "Multicultural Literature: The Impact It Has on Today's Students," St. John Fisher College, 2013. [6] M. Boles, "the Effects of Multicultural Literature in the Classroom," Access, 2006, [Online]. Available: http://commons.emich.edu/honors/62.

[7] R. E. Ferdig, J. Coutts, J. Dipietro, B. Lok, and N. Davis, "Innovative technologies for multicultural education needs," Multicult. Educ. Technol. J., vol. 1, no. 1, pp. 47-63, 2007, doi: 10.1108/17504970710745201. 